\title{
TEACHING RISK MANAGEMENT AND SAFETY AS A TOOL FOR SUPPORTING SUSTAINABLE DEVELOPMENT - A CURRICULUM DEVELOPMENT
}

\author{
Mohammad Shahriari \\ Chalmers University of Technology, Sweden
}

\begin{abstract}
Training of engineers as one of the main factors for implementing sustainability in industry is a key task. Due to this fact, the courses given in Chalmers should be adapted to the goal of sustainability. This could not be gained without integrating of risk assessment, as a tool of loss prevention, into different course curricula. To meet the demands, a course entitled "Risk Management and Safety" is offered two times a year to pre-service teachers that study in Chalmers master and doctoral programmes. This paper is concerned with presenting a method for developing a course curriculum including designing, control and evaluation of the projects as an essential part of the course. Industrial patterns have an important role especially in designing and evaluating the projects. The learning outcomes and the work efficiency are also controlled and evaluated through a questionnaire and personal interviews.
\end{abstract}

Key words: course development, curriculum development, sustainability, risk management, teaching

\section{Introduction}

Quality and sustainability are the main principles behind teaching in Chalmers University of Technology. In fact, sustainable development is increasingly achieving an interdisciplinary position in developing curricula of the courses given by different departments of Chalmers. The basic aim is to enable the learners as future teachers and engineers to make a sense of life and to develop the potential for peaceful coexistence with nature.

Sustainable development is maintaining a delicate balance between the human need to improve lifestyles and feeling of well-being, on the one hand, and preserving natural resources and ecosystems, on which we and future generations depend, on the other hand (Srinivas, 2009). The goal of sustainability in industry is to achieve safety in production activities, ensure human health, protect the environment and run the world ecosystem in 
acceptable steady-state conditions with regards to material, energy and population. In other words, to achieve sustainable industrial development, there is a need to minimize the losses in terms of human life, environmental damage, economy, life style quality and well being due to unknown factors/uncertainties. Therefore, risk management and safety as a state of freedom from unacceptable losses is an important element of sustainable development.

Rapid development of industries and human activities has created uncertainties and risk as the potential of unwanted events followed by some kind of losses. In fact, uncertainty is a major factor in matters of science, technology, health and the environment. New forms of technology, new medical treatments, the impact of certain substances on the air, water, and/or soil all have effects, both long and short term that cannot be completely predicted (Schultz, 2004). Therefore, risk management has rapidly developed as a tool for the regulation of industrial activities or environmental control as well as decision making for investment in different sectors (de Rocquigny, 2009). In addition, skilled people are needed to use risk management as a tool for controlling the losses. Importantly, universities are responsible for training teachers and engineers as the main actors in sustainable industrial development. Therefore, a course curriculum should be developed in order to meet the future needs and demands of engineers having both the knowledge and skills necessary to design and operate a plant free of unacceptable losses as one of the most important criterion of sustainable development. In addition, the learners should be trained in a way to be able to develop, improve and apply the products and processes, which are environmentally sustainable and economically sound. To fulfil these requirements, the students should be able to integrate principles of sustainable development and risk management procedure in their future careers (Kolluru, Bartell, Pitblado, \& Stricoff, 2006; Migilinskas \& Ustinovicius, 2008; Mock \& Wernke, 2011). It is of utter importance to be able to identify the uncertainties one might be faced with and also when something should be changed or a decision should be taken; to identify the hazards existing in the workplaces that may cause some kind of losses; to identify the causes of poor efficiency and increasing productivity by making highly efficient use of raw materials and energy; to reduce or eliminate the use and generation of hazardous substances; to reduce or eliminate the wastes that may cause economic losses; to reduce or eliminate the release of substances harmful to humans and the environment.

The tasks that need to be undertaken in future are much more complex and include the optimization of plants with the goal of finding safe and environmentally adapted and economically competitive processes. The design and control of the process or the production system and single pieces of equipment must, therefore, be improved in terms of reliability and safety. Accordingly, there is a need for engineers who know how to implement engineering disciplines in order to develop safe and environmentally sustainable processes/systems. Good knowledge of engineering disciplines is, however, not sufficient as engineers must also be able to make a simultaneous analysis of hazards and risks existing in a system. They must set up the global goals concerning safety, environmental and economic demands and avoid uncoordinated sub-optimization to protect the subsystem under his/her responsibility against any possible losses (Irandoust, Shahriari, \& Niklasson, 1999). 
As a matter of fact, accidents cost money and must be mainly paid for by the company. This cost is not like the cost of materials, equipment or wages. There is no return for the company or the injured employee on money spent as the result of an accident. Hence, an accident-free business is a profitable business and, of course, in the frame of the concept of sustainable development. Due to the aforementioned reasons, considerable efforts have been made to develop safer and more environmentally sustainable production systems and processes during the past decades. Most of this work has been enforced by national and international legislations (Rikhardsson \& Impgaard, 2002).

Indeed, risk assessment and management is viewed as a lens inside the sustainable climate, as a body through which all potential of losses can be reviewed. It can also be used as a lens for reviewing learning outcomes in preparing the students for implementing sustainable industries and society. In this case, integrating of risk assessment in other curricula could direct the students as the future operators towards sustainable thinking. Now, the question is how effectively do the students learn?

In a paper by Murray (2000), a debate on teaching students how to learn was initiated. The debate was based on research studies and also the opinions articulated by experts who have been involved in learning. The most important aspects that could be extracted from the debate were numerous.

1. The students learn best when they self-regulate the learning process. However, they should learn how to do it.

2. If faculties integrate self-regulation strategies into their teaching, students may absorb course materials more quickly.

3. The students need an instruction in using the strategies to increase their learning efficiency.

4. The research findings show that a way that teachers can help students structure their time and learning is by setting a clear course objective, giving plenty of examples to explain the main concepts, quizzing students frequently through regular assignments, providing a feedback on students' work and using mnemonic aids and learning devices.

In addition, the learning outcome should be assessed based on the programme learning goals by focusing on how students can demonstrate that the goals are being met. The learning outcomes must be measurable. Measures are applied to student work and may include: assignments, examples, tests, measuring student ability (project/case study) and students' attitude (course evaluation) (CSU Chico, 2011). The aforementioned principles were used as the base to design a course for teaching risk and safety at Chalmers University of technology.

\section{Aim of the study}

This study focuses on a case in development and evaluation of a 7.5-credit course curriculum in Chalmers entitled "Risk Management and Safety" as a tool to support sustainable 
development. The curricula development carried out was based principally on the relevant national and international teachers and industrial experts' ideas. The aim of this course is to give training to the master students and $\mathrm{PhD}$ candidates in how to apply their knowledge and technical skills more efficiently to protect people and the environment. The course prepares students to approach the technical skills required to identify hazardous scenarios in a complex system, to improve and modify it in terms of safety, productivity, quality and remaining environmentally benign. Besides, students should be able to handle the situations under uncertain conditions. The goal is to integrate safety into different engineering education and curriculum.

The main purpose of this paper is to highlight a method for developing the course curriculum as well as designing, carrying out, control and evaluation of the project works. The method of project design and control was applied to some case studies, i.e. a study concerning waste water, treatment of the ethylenediamine plant at AKZO NOBEL in Stenungsund, Sweden (Irandoust et al., 1999).

\section{Methodology}

Various models have been suggested for the development of curricula for study programmes in engineering (Kristin \& Moore, 2005; Chandra \& Kumar, 2006; Cowan \& Harding, 2006; Wiggins \& McTighe, 2006). However, the method suggested in this study is a simple three-stage backward method which is designed based on Wiggins and McTighe (2006) and Kristin and Moore (2005). In this study, the curriculum was designed in three stages by, firstly, identifying the design results, secondly, structuring the curriculum and, thirdly, implementation and evaluation.

In developing of the curriculum, some teachers and master students from Chalmers University (representing different fields including sustainable development) and some safety experts from industries, for instance, from AKZO NOBEL Stenugsund and Preem refinery Gothenburg, Sweden were involved.

The curriculum implementation was assessed and evaluated through the results of home assignments, workshops and the project works. Home assignments were designed based on the lecture given by the teachers. Individual subjects were evaluated by getting feedback from the course participants through filling in a questionnaire and an interview. The feedback from the students in terms of preparing and distributing the questionnaires, making interviews and analysing the points of view was performed by the students, and the results were discussed and finalized by the examiner. The final results of this qualitative evaluation were reported to the relevant master programme coordinators and the teachers as well. The examiner took advantage of the final analysis and results for improvement of the course. The method of the curriculum development is shown in Figure 1 (Appendix).

There are numerous advantages of this method compared with the traditional method of curriculum development. 
1. The students have been and are involved in the development and improvement of the existing state.

2. The students have an important role in developing the course through sharing of their project works with others in the course material.

3. The students are not limited to the course material given by the teachers. The assignments are designed in a way that the students find the answers by doing research.

4. Most of the time, the students are involved with team work.

5. Taking advantage of guest lecturers representing various experiences and involving the students with different activities could bring up a good interest for learning among the students.

6. To encourage the students in their own learning, an opportunity to propose and formulate/define their own projects, with supervisors' assistance and facilitation, is provided.

\section{Course structure and teaching methods}

The course consists of lectures given by different teachers, including experts from industries, workshops, seminars, project works/mini case studies, study visits and home assignments.

The course material is prepared on the basis of the participants' backgrounds. Every year, the contents of course material are changed on the basis of the course products and the results of the research in the fields of risk and safety. One of the most important principles in course material preparation is simplifying the models and submitting them in a more understandable way.

Any subject or lecture is followed by some workshop problems. The workshops are conducted by a group of students and are designed to provide more examples and real cases which help the students to understand the main concepts; to increase the effectiveness of learning by means of discussion between the group members and to increase the effectiveness of team working.

Confusing concepts are considered a major hazard in any course causing problems in understanding and communication. In this course, workshops together with assignments are used to eliminate/minimize this problem. Workshops help the students to increase their perception by means of group discussion. Assignments are mostly used for evaluation the level of individual understanding, for instance, to see whether the students can either recognize the distinction between hazard, risk, uncertainty and accident or understand the relationship between reliability and safety. In fact, $40 \%$ of the total mark of the course is allocated to the assignments. It should be noted that the course has no written exam.

In order to increase the knowledge of students and also to show how risk assessment is integrated into different field of activities in the real world, some key subject seminars are arranged. The main tasks of student seminars are to extend the involvement of the students 
in learning activities and to increase their knowledge concerning some important subjects as a part of the course curriculum. The lecturers in these seminars are invited from industries, and the rest are conducted by the students who have participated in the course. As far as the students' seminars are concerned, the students are requested to present some cases concerned with integration of safety into their field in the classroom. A seminar is an optional part of the course.

Study visit is another tool to give the students an opportunity to compare what they have learned in the course with what is applied in reality. During the course, the students visit one or two plants/workstations.

Project work by which risk assessment is integrated into other fields is an important and crucial part of the curriculum design. In other words, it is an essential section where the knowledge obtained from the course is applied assessing the risk of a complex system, for instance, production system. The project is carried out by a group of students and is expected to encourage critical thinking, creativity and involvement among both students and supervisors.

Zhou, Dalsgaard, Kolmos and Xiangyun (2009) have developed a model based on an empirical study regarding group creativity development in engineering students in a problem/project based learning environment. According to Zhou et al. (2009), in problem/project based learning (PBL) context, the students can develop their group creativity by self-directed learning and peer learning focused on teamwork. In the meantime, group creativity will be influenced by the roles of the project and supervisors. In PBL, the supervisor is expected to be able to provide good strategies for learning and thinking.

Peer learning has been noted to be among the most effective learning approaches (Zhou et al., 2009). This study and many other studies show that though creativity initiates in the mind, individual actions and interactions among or between the learners and the environment makes the creativity fundamentally a social-cultural concept, especially when we focused on creative work in collaboration (Zhou, et al., 2009).

Due to the aforementioned facts, the project was recommended to be compulsory. Furthermore, $50 \%$ of the mark of the course is allocated to the project work. About four weeks of work are required for a group of students to fulfil the objectives of the project.

The project ideas concerning the integration of risk assessment and safety in production, product quality, maintenance, hazardous waste, etc. are generated mainly in cooperation with industrial companies, for instance, Preem refinery in Gothenburg and AKZO NOBEL in Stenungsund, Sweden. The progress of the project and the learning outcomes is controlled in different ways by the supervisor in co-operation with the examiner. Projects should be conducted with regards to the goal and the learning outcomes of the course. The students are required to present the project, both in writing and orally.

Each project is to be assessed by the supervisors and the examiner. The following mark format is a general guide to assessment, indicating the relative significance of different aspects of a completed project (Table 1).

The course is evaluated through a written questionnaire and personal interviews. The results are used to improve the course further. The former evaluations showed that the stu- 
dents highly appreciated a close relation to and input from the industrial partners through seminars, study visit and project works. The results of qualitative interviews showed that the students strongly approved of being oriented towards a real case of industrial relevance.

Table1. General guide of project assessment (modified after Irandoust et al., 1999)

\section{Oral presentation}

1. Quality of the slides is good.

2. Presentation reflects the content of the report.

3. Presentation is acceptable from the logical and pedagogical points of view.

4. Performance could bring up a good interest among the audience.

5. Questions could be answered properly.

\section{Report}

1. Abstract gives a clear picture about the project.

2. Problem is formulated properly and the aim of the study is explained clearly.

3 . The methodology is selected and used properly.

4. Theoretical framework supports the study.

5. Analysis of the case/problem under the study is carried out in a reasonable way.

6 . The study is supported by relevant and reliable references.

1. Objectives of the study are fulfilled.

2. Title is relevant to the contents of the study.

3. Results: the quality of interpretation and discussion of the results is within the context of the related knowledge and can reach the aim of the study.

4. Conclusion is extracted correctly from the existing material.

1. Report organization and structure: different parts of the report are properly coordinated. Lines of argument are clear throughout the report.

Project mark

$(\%)$

2. Report presentation: layout, standard of production or reproduction of figures and photographs, and length of the document are as requested in the course plan.

Total

It was also interesting to find out what and how the students have learned, how they have understood and on what level they have been taught. This is by no means an easy task. Continuous follow-up in this matter was important in determining how the students developed their skills. There is always a variation in the level of understanding among students. In order to reveal both the variation and level of understanding, deep discussions on qualitatively different types of questions between some individual students and the examiner are to be used, though these activities are time-consuming.

\section{Conclusion}

The master's course programmes require active pedagogy. Attempts have been made to design different effective tools, such as workshops, assignments and project works to satisfy the students' needs. One basic requirement of crucial importance is the industrial relevance of the chosen problems/projects to motivate active students' participation. 
As far as the project work is concerned, essential abilities for students' learning should include problem identification and problem formulation related to risk assessment in their fields.

On the basis of course evaluation, some achievements are the following: clear definition of course objectives, clear description of requirements and instructions, communication and timely feedback, encouraging workshops, especially when the industrial cases are provided. Moreover, study visits provide a forum for discussion, exchange and learning. During the study visits, the students have an opportunity to establish professional contacts that might potentially be used for developing ideas for new projects or their master thesis, or a future job.

A central factor in the project supervision has been the regular meeting between the students and the supervisor and/or the examiner, where the actual case could be discussed. The main role of the supervisor is to be the catalyst during the students' analysis and solution of the problem. Every project should encourage critical thinking, creativity and involvement among both students and the supervisors. The keys to success are engagement of students in problem definition and formulation, efficiency of the teamwork, communication between the supervisor and the group and also between the group members, clear definition of objectives and goals of the study, explicit and clear criteria for assessment and judgement of the work at both individual and group levels, taking advantage of different cultures and backgrounds among the group members when the group is heterogeneous in terms of different ways of analysing problems. In the assessment of projects, the industry representative should be strongly involved.

\section{References:}

Chandra, C., \& Kumar, S. (2006). Supply chain design curriculum: Models and methods development. Information and Operations Management Education, 1(3), 249-280.

Cowan, J., \& Harding, A. G. (1986). A logical model for curriculum development. British Journal of Educational Technology, 17(2), 103-109. DOI: 10.1111/j.1467-8535.1986.t b00500.x.

CSU Chico. (2011). Assessment of student learning - strategies for assessing learning outcomes. Retrieved March 19, 2010, from http://www.csuchico.edu/vpaa/assessment/too lbox/assessmentStrategies.shtml

de Rocquigny, E. (2009). Quantifying uncertainty in an industrial approach. An emerging consensus in an old epistemological debate. S:A:P:I:EN:S, 2.1/2009, 2(1). Retrieved March 23, 2010, from http://sapiens.revues.org/index782.html

Irandoust, S., Shahriari, M., \& Niklasson, C. (1999). Environmentally sustainable processtechnology. An international master's programme at Chalmers University of Technology, Sweden: Formulation, performance and evaluation of case studies. Proceedings of the 3rd Baltic Region Seminar on Engineering Education, Göteborg, Sweden, 
3-5 September 1999 (pp. 1-4). UICEE, Chalmers University of Technology, Göteborg, Sweden.

Kolluru, R. V., Bartell, S. M., Pitblado, R. M., \& Stricoff, R. S. (2006). Risk assessment and management handbook, 1996: For environmental, health, and safety professionals. New York: McGraw-Hill.

Kristin, L. G., \& Moore, F. M. (2005). Including students and teachers in the co-design of the enacted curriculum. Paper presented at the NARST 2005 Annual Meeting (Dallas, Texas). Retrieved December 20, 2005, from https://www.msu.edu/ gunckelk/NARST 2005GunckelMoore.pdf

Migilinskas, D., \& Ustinovicius, L. (2008). Methodology of risk and uncertainty management in construction's technological and economical problems. The 25 th international symposium on automation and robotics in construction (ISARC 2008), June 26-29 2008, Lithuania. In E. Zavadskas, A. Kaklauskas \& M. J. Skibniewski (Eds.), Selected papers (pp. 789-795). Vilnius: Technika. DOI: 10.3846/isarc.20080626.789.

Mock, T., \& Wernke, T. (2011). The universal principles of sustainable development. Part 3 in the fractal sustainable development trilog. By sustainable land development initiative. Retrieved February 7, 2011, from http://www.triplepundit.com/2011/02/univer sal-principles-sustainable-development/

Murray, B. (2000). Teaching students how to learn. Monitor on Psychology, 31(8), 64-68.

Rikhardsson, P. M., \& Impgaard, M. (2002). The cost of company occupational accidents: An activity-based analysis using the SACA method. ASSE professional development conference and exposition, June 9-12, 2002, Nashville, Tennessee, TN. Paper number 02-649. Retrieved December 20, 2002, from http://www.onepetro.org/mslib/servlet/on epetropreview?id=ASSE-02-649\&soc=ASSE

Schultz, N. (2004). Uncertainty. That which cannot be known. Retrieved March 27, 2010, from http://www.beyondintractability.org/essay/fact_finding_limits

Srinivas, H. (2009, November). SD features definitions. Retrieved March 26, 2010, from http://www.gdrc.org/sustdev/definitions.html

Wiggins, G., \& McTighe, J. (2006). Understanding by design: Professional development workbook (Expanded 2nd ed.). Upper Saddle River, New Jersey: Pearson Education, Inc.

Zhou, C., Dalsgaard, N. J., Kolmos, A., \& Xiangyun, D. (2009). Group creativity development in engineering students in a problem and project based learning environment. Proceedings of the 2nd International Research Symposium on PBL, 3-4 December 2009, Melbourne, Australia (pp. 1-8). Retrieved December 20, 1999, from http://vbn. aau.dk/files/19153167/download.pdfkonference.pdf 


\section{Appendix}

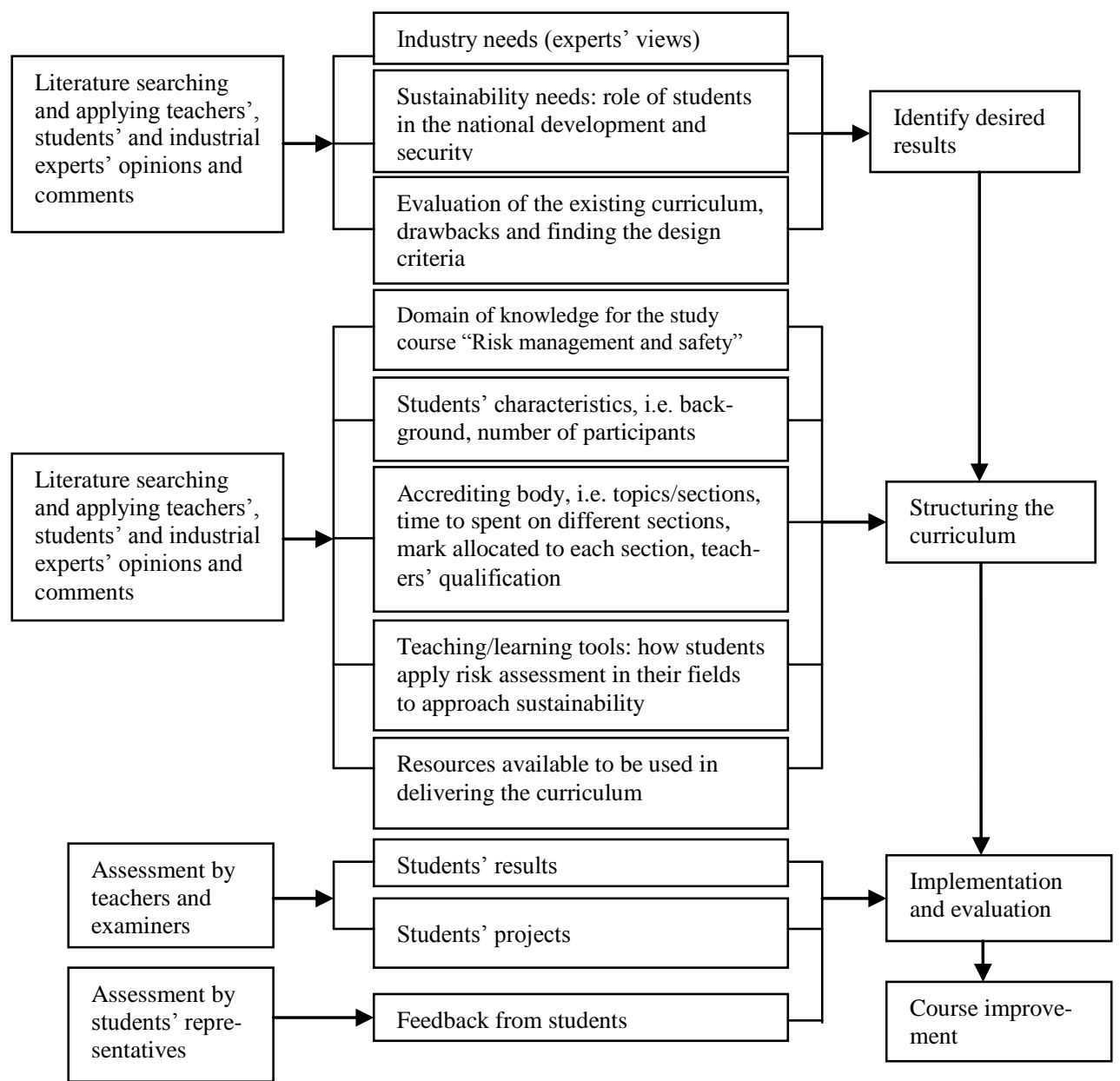

Figure 1. Methodology for designing course curriculum (developed based on Wiggins and McTighe, 2006)

\section{Correspondence:}

Mohammad Shahriari, PhD, Department of Product and Production Development, Chalmers University of Technology, SE-412 96 Gothenburg, Sweden. Phone: +46317722944; Fax: +46317723660. Email: mohammad.shahriari@chalmers.se 